\title{
PRÁTICAS E PERCEPÇÕES DE EDUCADORES QUANTO AO ALEITAMENTO MATERNO
}

\section{Educators' breastfeeding-related practices and perceptions \\ Prácticas y percepciones de educadores sobre la lactancia materna}

\author{
Bianca da Silva Alcantara Pereira (OrcID) \\ Escola de Enfermagem de Ribeirão Preto - EERP/USP - Ribeirão Preto (SP) - Brasil
}

Elisangela Bellafronte (Lattes)

Universidade Estadual do Oeste do Paraná - UNIOESTE - Foz do Iguaçu (PR) - Brasil

Maria de Lourdes de Almeida (OrcID)

Universidade Estadual do Oeste do Paraná - UNIOESTE - Foz do Iguaçu (PR) - Brasil

Rosane Meire Munhak da Silva (Lattes)

Universidade Estadual do Oeste do Paraná - UNIOESTE - Foz do Iguaçu (PR) - Brasil

Reinaldo Antonio Silva Sobrinho (OrcID)

Universidade Estadual do Oeste do Paraná - UNIOESTE - Foz do Iguaçu (PR) - Brasil

Adriana Zilly (OrcID)

Universidade Estadual do Oeste do Paraná - UNIOESTE - Foz do Iguaçu (PR) - Brasil

\section{RESUMO}

Objetivo: Conhecer as práticas e percepções de profissionais da educação sobre o aleitamento materno. Métodos: Estudo exploratório e descritivo, de abordagem qualitativa. A coleta de dados ocorreu em 2015, com 19 profissionais da educação atuantes em berçários das creches de um município de fronteira do Sul do Brasil. Utilizou-se a técnica do Discurso do Sujeito Coletivo para organizar e tabular os dados qualitativos. Resultados: A construção dos discursos do sujeito coletivo permitiu visualizar que, na percepção das professoras, o aleitamento materno é considerado negativo e não há benefícios nessa prática para crianças matriculadas no berçário I, principalmente pela indisponibilidade da mãe em ir à creche. Deste modo, considerou-se o local como não sendo um bom lugar para mãe amamentar. A percepção da profissional sobre o aleitamento materno o coloca como uma barreira à sua prática profissional e, por isso, o ensino, a manutenção e a promoção à amamentação não ocorrem. Além disso, foram mencionadas dificuldades quanto à infraestrutura escolar para a implementação do aleitamento. Conclusão: As profissionais consideram que o aleitamento materno pode ser uma barreira à sua prática profissional, relatam as dificuldades existentes para essa prática e, efetivamente, não o incentivam.

Descritores: Aleitamento Materno; Berçários; Educação Infantil; Educação em Saúde.

\begin{abstract}
Objective: To know education professionals'breastfeeding-related practices and perceptions. Methods: Descriptive and exploratory study, with a qualitative approach. Data collection took place in 2015, with 19 education professionals working in nurseries of day-care centers in a bordering municipality of Southern Brazil. The Collective Subject Discourse technique was used in order to organize and tabulate the qualitative data. Results: The construction of the collective subject discourses led to the evidence that, in the teachers' perception, breastfeeding is considered negative and there are no benefits in this practice for children enrolled in nursery I, mainly because the mothers could not manage to go to the daycare center. Thus, the place was regarded as an unsuitable location for the mother to breastfeed. The professional's perception of breastfeeding renders it a hindrance to their professional practice and, therefore, the teaching, maintenance and promotion of breastfeeding doesn't occur. Moreover, issues regarding the school infrastructure were mentioned as difficulties for the implementation of breastfeeding. Conclusion: The professionals consider that breastfeeding may represent a barrier to their professional performance; they report the existing difficulties for such practice and do not actually encourage it.
\end{abstract}

Descriptors: Breastfeeding; Nursery; Childhood Education; Health Education. 


\section{RESUMEN}

Objetivo: Conocer las prácticas y percepciones de profesionales de la educación sobre la lactancia materna. Métodos: Estudio exploratorio y descriptivo de abordaje cualitativo. La recogida de datos se dio en 2015 con 19 profesionales de la educación que actúan en los nidos de las guarderías de un municipio de la frontera del Sur de Brasil. Se utilizó la técnica del Discurso del Sujeto Colectivo para organizar y tabular los datos cualitativos. Resultados: La construcción de los discursos del sujeto colectivo ha permitido visualizar que la lactancia materna es considerada negativa en la percepción de las profesoras y que no hay beneficios de esa práctica para los bebés matriculados en el nido I, en especial por la indisponibilidad de la madre para irse a la guardería. De esa manera, se consideró el sitio inadecuado para una madre amamantar. La percepción de la profesional sobre la lactancia materna la identifica como una barrera a su práctica profesional y, por eso, la enseñanza, la manutención y la promoción del amamantamiento no se dan. Además de eso, se han mencionado las dificultades de la infraestructura escolar para la implementación de la lactancia materna. Conclusión: Las profesionales consideran que la lactancia materna puede ser una barrera a su práctica profesional, relatan las dificultades que hay para esa práctica y, efectivamente, no la incentivan.

Descriptores: Lactancia Materna; Casas Cuna; Crianza del Niño; Educación en Salud.

\section{INTRODUÇÃO}

De acordo com Pesquisas Nacionais de Saúde (1986, 1996, 2006 e 2013), os indicadores de aleitamento materno apresentaram tendência ascendente no Brasil, com ganhos entre 1986 e 2006, e estabilização em 2013. Já a amamentação continuada até o segundo ano de vida da criança manteve-se estável entre 1986 e 2006, sendo o único indicador com aumento da prevalência entre 2006 e $2013^{(1)}$.

Apesar do incentivo, apoio e estímulo à prática do aleitamento materno proporcionada pelas políticas de saúde e pela ação dos profissionais da educação e da saúde, os índices de aleitamento materno ainda estão distantes das taxas consideradas ideais pela Organização Mundial da Saúde (OMS) ${ }^{(2)}$.

Em países de baixa e média renda, como o Brasil, a importância do aleitamento é reconhecida. Nesses locais, apenas $37 \%$ das crianças menores de 6 meses são amamentadas exclusivamente. A amamentação protege a criança contra infecções, desnutrição e má oclusão, aumenta a inteligência e pode provavelmente reduzir o excesso de peso e diabetes. $O$ aumento da amamentação, mundialmente, poderia evitar 823.000 mortes anuais em crianças menores de 5 anos $^{(3)}$.

Para o sucesso do aleitamento materno, profissionais da saúde e da educação, além dos familiares, precisam compreender que essa ação deve ser apoiada e incentivada. Logo, os Centros Municipais de Educação Infantil (CMEls), ou creches, devem ser entendidos como locais onde o aleitamento materno deveria ser encorajado e facilitado, e os profissionais da educação devem fazer parte dessa prática como grandes apoiadores ${ }^{(4)}$.

Além disso, ao se considerar que quase $25 \%$ da população economicamente ativa é constituída por mulheres com filhos pequenos, os quais necessitam permanecer em creches ainda no período da lactância, é fundamental que esses locais, assim como os profissionais que ali atuam, encontrem-se preparados para incentivar a manutenção do aleitamento materno(5).

Neste contexto, o presente trabalho teve por objetivo conhecer as práticas e percepções dos profissionais da educação sobre o aleitamento materno.

\section{MÉTODOS}

Pesquisa exploratória e descritiva com análise qualitativa dos dados, realizada em Foz do Iguaçu, Paraná, Brasil.

Dos 33 CMEls do município, 15 deles possuem turmas de berçário I e atendem crianças de seis meses a um ano. De forma geral, atendem crianças de 6 meses a 4 anos de idade, apenas meio período (matutino ou vespertino, de acordo com a escolha materna), onde recebem alimentação por meio da profissional da educação e sua auxiliar. Existe um local destinado ao manuseio da alimentação e, em alguns, existe o espaço do lactário e do solário( ${ }^{(6)}$.

Durante a coleta de dados, quatro centros estavam com seus berçários fechados por falta de profissionais ou problemas estruturais. Portanto, realizou-se o presente estudo em apenas $11 \mathrm{CMEls}$ do município investigado.

De acordo com a Secretaria de Educação do Município de Foz do Iguaçu, em cada turma do berçário I, de cada CMEI, deveriam estar atuando dois profissionais da educação, perfazendo um total de 22 profissionais da educação participantes da pesquisa( ${ }^{(6)}$. 
Os critérios de inclusão para a pesquisa foram aceitar participar e estar atuando, no mínimo, há seis meses na profissão. Excluíram-se três profissionais que estavam afastadas do trabalho por licença de saúde.

A coleta de dados ocorreu de abril a junho de 2015, nas dependências dos CMEls, com as profissionais, por meio de agendamento prévio via telefone, com duração de cerca de 20 minutos. $O$ instrumento semiestruturado foi previamente avaliado por dois profissionais especialistas nas áreas de enfermagem e educação, através de questões abertas, qualitativas, com a finalidade de extrair suas práticas e percepções a respeito do aleitamento materno no CMEI.

Quanto ao material verbal a ser coletado na entrevista com os participantes, enquadrou-se em cinco questões norteadoras: 1: Durante a vivência e a prática no cuidado de crianças menores de um ano, como você percebe o aleitamento materno no CMEI? Houve benefícios para as crianças?; 2: O CMEl é um lugar estruturado para amamentar? Quais são as facilidades e dificuldades para o aleitamento materno?; 3: O que você faz quando uma criança que ainda amamentada é matriculada?; 4: Quais as suas ações no ensino, manutenção e incentivo ao aleitamento materno no CMEI no primeiro ano de vida?; 5: Qual sua relação com a mãe que amamenta? Vocês conversam sobre suas expectativas e experiências sobre amamentação?

Adotou-se como estratégia metodológica desta pesquisa qualitativa a construção do Discurso do Sujeito Coletivo (DSC), cujo processo metodológico orienta-se sistematicamente por meio de elementos específicos para o seu desenvolvimento, sendo eles: a ideia central (IC), as ancoragens (ACs), as expressões-chave (ECH) e, como produto final desse processo, os DSC ${ }^{(7)}$.

Nesta pesquisa, as ancoragens não foram encontradas, já que esse elemento surge somente em situações em que aparecem, no material verbal, marcas discursivas explícitas dessas afirmações genéricas ${ }^{(7)}$. Desta forma, as figuras metodológicas de linguagem para compor o Discurso do Sujeito Coletivo usadas foram a ideia central (IC) e as expressões-chave (ECH).

Ressalta-se que, no desenvolvimento da pesquisa, atenderam-se as diretrizes e normas da Resolução 466/2012 do Conselho Nacional de Saúde, sendo o estudo aprovado pelo Comitê de Ética em Pesquisa da Universidade Estadual do Oeste do Paraná, sob Parecer nº 931.596.

\section{RESULTADOS E DISCUSSÃO}

Participaram da pesquisa 19 profissionais, todas do sexo feminino, vinculadas a 11 CMEls do município.

A primeira questão norteadora diz respeito à vivência e à prática no cuidado de crianças menores de um ano, como a profissional percebe o aleitamento materno na creche e se houve benefícios. As respostas das entrevistadas evidenciaram um caráter discursivo que possibilitaram a formação de cinco DSCs (Tabela I).

Tabela I - Apresentação das ideias centrais e Discursos do Sujeito Coletivo sobre a percepção do aleitamento materno nos centros municipais de educação infantil e a existência de benefícios. Foz do Iguaçu, Paraná, Brasil, 2015.

\begin{tabular}{|c|c|}
\hline Ideias centrais & Discurso do sujeito coletivo \\
\hline IC 1: Indisponibilidade da mãe & $\begin{array}{l}\text { DSC 1: "Eu não percebo isso. As mães não vêm amamentar porque precisam } \\
\text { trabalhar, não fazem ordenha, portanto não há benefício algum para a criança." }\end{array}$ \\
\hline IC 2: Praticidade no aleitamento materno & $\begin{array}{l}\text { DSC 2: "O peito é prático, tem mãe que não quer dar outro alimento, mesmo } \\
\text { depois dos seis meses." }\end{array}$ \\
\hline IC 3: Desmame e adaptação & $\begin{array}{l}\text { DSC 3: "A maioria vem desmamada, seria ideal que toda criança fosse } \\
\text { desmamada, pois a adaptação é mais rápida, pra tirar é um sofrimento e } \\
\text { pra nós é um trabalho árduo. Essas mães deveriam ser preparadas antes do } \\
\text { início do ano letivo. Não tenho autonomia e liberdade para incentivar que a } \\
\text { mãe venha amamentar no CMEI, se ela quiser não vou proibir, mas ela vai ser } \\
\text { desencorajada pelas professoras." }\end{array}$ \\
\hline IC 4: Criança saudável & $\begin{array}{l}\text { DSC 4: "Sim, a vida da criança é mais saudável, a criança que não mama no } \\
\text { peito vive doente." }\end{array}$ \\
\hline IC 5: Estabilidade emocional da criança & $\begin{array}{l}\text { DSC 5: "Sim, elas precisam desse contato com a mãe, valorizar o laço e o vínculo } \\
\text { afetivo, a criança se sente mais segura, elas não podem ser terceirizadas." }\end{array}$ \\
\hline
\end{tabular}

IC: Ideia Central; DSC: Discurso do Sujeito Coletivo 
A indisponibilidade da mãe ao aleitamento materno, apresentada como IC, está associada às mudanças na vida da mulher e à necessidade de atender às demandas do bebê, sua vida profissional e pessoal. Fatores socioeconômicos são decisivos na antecipação ou retardo na matrícula, que tende a ser um momento delicado na vida da mulher ${ }^{(8)}$.

Ademais, considerando que o aleitamento materno exclusivo não terá continuidade, as depoentes não compreendem que, mesmo desta forma, a amamentação trará benefícios para a criança. Embora não possam amamentar constantemente, a mãe deverá ser encorajada e, se possível, orientada às práticas para manter esse ato importante para o bebê até os dois anos de vida. Dentre as orientações, destacam-se: a amamentação com maior frequência quando estiver em casa; evitar a utilização de mamadeiras e a oferta da alimentação em um copo ou colher; durante a jornada de trabalho, realizar ordenha para esvaziar as mamas e acondicionar o leite em congelador ${ }^{(9)}$; sempre que possível, amamentar a criança ao longo do dia, mesmo estando em CMEl, uma vez que a Consolidação das Leis do Trabalho, em seu art. 396, assegura intervalos na jornada de trabalho para as mulheres que estão amamentando(10).

Por outro lado, na IC 2 surgiu a questão da praticidade no aleitamento. Em uma pesquisa qualitativa realizada no interior de São Paulo, com foco na adesão ao aleitamento materno, apontou-se sua facilidade como um fator que contribui para sua manutenção. Sob a ótica familiar, a amamentação é vista com bons olhos por não ter custo e preocupação com o preparo e, para o Estado, por contribuir para a redução de gastos com internamentos, acarretando economia de consultas médicas e tempo perdido pela mãe trabalhadora ${ }^{(11)}$.

Contudo, apesar de tantas vantagens, pesquisas revelam que as mães amamentam exclusivamente, no máximo, até ao quarto mês de vida de suas crianças, e que, dentre os fatores responsáveis pelo desmame precoce, destacam-se a influência da família, questões culturais e financeiras, e a falta de orientação ${ }^{(12,13)}$. Nessa perspectiva, compreende-se que o aleitamento materno não tem sido promovido por toda a sociedade, conforme preconiza a $\mathrm{OMS}^{(14)}$, realidade também evidenciada no presente estudo.

$\mathrm{Na}$ IC 3 e seu respectivo DSC, as profissionais acreditaram que o ideal é que a criança venha desmamada antes da matrícula e, se a mãe for amamentar no local, serão desencorajadas pelas professoras. Experiências pessoais e familiares influenciam essa prática e, mesmo pessoas mais esclarecidas sobre o assunto, como os profissionais da saúde e da educação, precisam ser encorajadas e apoiadas constantemente para o sucesso da manutenção do aleitamento materno ${ }^{(11,12,15)}$.

Na sequência surge o DSC 4, que revela que as profissionais conhecem e vivenciam a importância do aleitamento materno, pois a prática evita o aparecimento de várias doenças e, principalmente, pode evitar cerca de 820.000 mortes todo o ano(14), além de atuar como agente tranquilizador da criança no aspecto psicológico, auxiliando na promoção do desenvolvimento intelectual(16). Quanto aos prejuízos em curto prazo causados pelo desmame precoce, destaca-se a baixa imunidade da criança, que poderá favorecer as morbidades, tais como: infecções comuns, alergias, diarréia, doenças respiratórias, desnutrição, entre outras, e predispõem a morbidades em longo prazo, tais como: hipertensão, colesterol alto, obesidade e diabetes do tipo $2^{(13,14,17-19)}$.

Por volta do décimo mês de vida, as habilidades motoras impulsionam a exploração do ambiente humano ou inanimado. Essa característica permite que a criança fique envolvida nessas atividades, parecendo por muitos instantes ter se esquecido da mãe. Contudo, a criança ainda retoma a lembrança e necessita do reabastecimento emocional, ou seja, o contato físico com a mãe ${ }^{(20)}$, como relatado pelas entrevistadas na IC 5, DSC 5. Por esse motivo se faz tão importante a presença da mãe no $\mathrm{CMEI}$, mesmo após os 6 meses de idade do bebê.

A segunda questão norteadora questiona se o CMEl é um bom lugar para amamentar e quais são as facilidades e dificuldades para o aleitamento materno, da qual emergiram as ICs e DSCs que são apresentados na Tabela II.

Nesta questão, todas as ICs e discursos que emergiram do material verbal das participantes evidenciam que o CMEI não é um bom lugar para o aleitamento materno e que não existem facilidades para essa prática, corroborando os achados de outro estudo, em que a maioria das creches públicas não possuía estrutura para o incentivo e os profissionais não estavam atualizados com as recentes recomendações sobre aleitamento materno e alimentação complementar $(\mathrm{AC})^{(21,22)}$

A falta de ações apenas reflete o vazio, a lacuna na formação inicial e, até mesmo, continuada do profissional da educação. Sugerir horário para amamentação é imposição de rotina a uma necessidade fisiológica, é uma maneira de criar barreiras para a mãe amamentar.

Uma revisão realizada há cerca de uma década, envolvendo pesquisas brasileiras sobre amamentação em creches, demonstrou que o tema nesses ambientes era pouco explorado, que as creches precisavam se organizar em relação às rotinas de acolhimento das mães para amamentar, e que ainda havia necessidade de capacitação para que os educadores pudessem refletir e aprimorar suas práticas sobre ao aleitamento materno ${ }^{(22)}$. 
Tabela II - Apresentação das ideias centrais e Discursos do Sujeito Coletivo sobre dificuldades e facilidades para aleitamento materno nos centros municipais de educação infantil. Foz do Iguaçu, Paraná, Brasil, 2015.

\author{
Ideias centrais \\ IC 6: $O$ aleitamento materno no CME \\ atrapalha a rotina \\ IC 7: O aleitamento materno no CMEI \\ dificulta o desmame e adaptação da \\ criança
}

IC 8: O CMEI não é um bom lugar, porque a mãe não tem disponibilidade

IC 9: O CMEI não é um bom lugar, DSC 9: "Aqui não é um bom lugar, porque, se uma criança vê a outra mamando, porque desperta as outras crianças vai querer também."

para o AM

IC: Ideia Central; DSC: Discurso do Sujeito Coletivo; AM: aleitamento materno

Outro estudo destaca que a creche pode e deve ser considerada um local para a educação das mães em condições socioeconômicas menos privilegiadas em relação às práticas de manutenção do aleitamento materno até os 2 anos $^{(23)}$.

Levando isso em consideração, meios devem ser encontrados, uma vez que amamentar é uma prática a qual não se devem medir esforços para que a mãe tenha total liberdade de continuar. Ademais, o apoio à nutriz, por parte da família, da sociedade, dos profissionais de saúde e do Estado, é um eixo fundamental à efetividade do direito à amamentação(13), uma vez que a criança tem direito à ser amamentada e é dever das instituições oferecer condições para o sucesso da amamentação(24).

Embora não se tenha uma política de amamentação explícita nos serviços de educação infantil, é também dever dessas instituições e de todos os cidadãos garantir o direito à saúde e à amamentação, assegurado à criança desde a Constituição Federal de 1988 (25). Portanto, é de extrema importância que haja difusão de programas de ação continuada voltados para a alimentação infantil, envolvendo as equipes multiprofissionais e os CMEls locais.

A exemplo disso, alguns municípios têm incorporado, mesmo que de forma individual, em seus projetos de lei, a garantia da amamentação em CMEls. O município de São Paulo, por exemplo, com o Projeto de lei n $416 / 2016$, busca estabelecer que as unidades destinem uma sala para que as mães possam amamentar seus filhos ou para que possam retirar o leite a qualquer momento, garantindo privacidade. Tal projeto também enfatiza que as creches devem dispor de uma estrutura adequada para refrigeração e armazenamento do leite ${ }^{(26)}$.

Na IC 6, o aleitamento materno atrapalha a rotina e não há espaço para essa prática. A divisão do tempo é predominante na organização da rotina de instituições que atendem crianças pequenas, o que dificulta o trabalho educacional pedagógico na formação do sujeito em múltiplas dimensões ${ }^{(27)}$. Essa prática tende a abreviar a oportunidade da criança vivenciar a intensidade da pluralidade de saberes, a diversidade de raça, credo e gênero, sentimentos, ânsias e fantasias, ou seja, a creche, com sua rotina rígida, uniforme e homogeneizadora, parece dificultar a vivencia dos direitos da criança já instituídos.

No presente estudo, sinalizou-se a falta de espaço como entrave para o aleitamento dentro da instituição. Conforme a Resolução nº 0162/05 da Secretaria da Saúde do Estado do Paraná (SESA) ${ }^{(28)}$, esse espaço deveria existir, já que é uma norma para as instituições, particulares, públicas ou filantrópicas. Numa pesquisa acerca das condições desiguais como motivo para interrupção da amamentação, os autores também constataram que, apesar da lei existente, não havia seu cumprimento( ${ }^{(29)}$.

Em um estudo sobre a prevalência e os fatores de desmame precoce na creche, foram encontradas $34,8 \%$ das crianças em aleitamento materno exclusivo e $57,1 \%$ em aleitamento materno não exclusivo, sendo o principal motivo referido pelas mães para o desmame precoce a necessidade de trabalhar $(26,1 \%)^{(4)}$. Frente a essa realidade, 
a creche deveria ser um local de proteção e promoção da amamentação, fato que não vem acontecendo, já que o aleitamento materno é considerado negativo por atrapalhar o desmame e a adaptação da criança na instituição, de acordo com o IC 7 e seu respectivo DSC.

$\mathrm{Na}$ IC 8, as participantes referem que o aleitamento materno não ocorre pelo fato das mães trabalharem, sendo um empecilho para a prática. O problema seria a disponibilidade da mãe, e não o espaço do CMEI em si. Portanto, são necessárias intervenções com o objetivo de reduzir as barreiras para as mães trabalhadoras amamentarem, como a existência de salas de amamentação e pausas na jornada de trabalho para o aleitamento materno, que já é garantido por lei ${ }^{(28)}$. Essas intervenções são de baixo custo e podem reduzir a ausência e melhorar o desempenho, o comprometimento e a retenção da força de trabalho ${ }^{(30,31)}$.

Outra dificuldade apresentada na amamentação está exposta na IC 9. As professoras afirmam que o aleitamento materno no CMEI desperta em outras crianças a vontade de mamar no seio materno. O cheiro do leite e o calor materno acalmam o bebê e estimulam o afeto no binômio mãe-bebê. Partindo desse princípio, é possível perceber que, de fato, o cheiro do leite de outra mãe, ou mesmo de uma educadora em lactação, pode despertar no bebê suas lembranças maternas ${ }^{(32)}$.

O olfato desempenha um papel essencial no desenvolvimento afetivo, visto que a relação do bebê com o odor ocorre de maneira forte, pois ele associa cheiros como o do seio, do suor axilar e do pescoço da mãe. Com apenas sete dias de vida, o bebê já consegue diferenciar o cheiro de outras mães em lactação do de sua mãe, contudo, odores maternos parecem desempenhar um papel tranquilizador e favorecer o adormecimento do bebê $\hat{e}^{(33)}$.

Na sequência da apresentação dos resultados dos discursos, a terceira questão norteadora trata do que a profissional faz quando uma criança que ainda amamenta é matriculada (Tabela III).

Tabela III - Apresentação das ideias centrais e Discursos do Sujeito Coletivo sobre como proceder com crianças em aleitamento materno no centro municipal de educação infantil. Foz do Iguaçu, Paraná, Brasil, 2015.

\begin{tabular}{ll}
\hline Ideias centrais & Discurso do sujeito coletivo \\
\hline IC 10: Redução da carga horária & DSC 10: “Quando só mama e não aceita outro alimento, a gente pede pra mãe não \\
da criança no CMEI & deixar o dia todo até adaptação, porque elas não vêm dar de mamar. Assim, não \\
& ficam tanto tempo sem comer. As mães querem tanto uma vaga que elas escondem \\
& se a criança mama no peito, se elas comem algo além do leite. Mas nós percebemos, \\
& pedimos que, no começo, venham buscar mais cedo." \\
\hline
\end{tabular}

IC: Ideia Central; DSC: Discurso do Sujeito Coletivo

A redução da carga horária de fato é uma estratégia bastante utilizada na adaptação da criança. O período de transição pode levar de 6 dias a 2 semanas, dependendo do temperamento da criança e se ela já tem, ou não, o costume de ficar longe dos pais. Nesse transcurso da adaptação, em geral, a criança frequenta a creche em período parcial(34).

Quanto à quarta questão norteadora, que trata das ações da profissional no ensino, manutenção e incentivo do aleitamento materno no CMEI no primeiro ano de vida, os discursos sugerem que a maioria não realiza nenhuma ação para incentivar ou manter o aleitamento materno (Tabela IV).

Tabela IV - Apresentação das ideias centrais e Discursos do Sujeito Coletivo sobre ações para o ensino, manutenção e incentivo ao aleitamento materno no primeiro ano de vida. Foz do Iguaçu, Paraná, Brasil, 2015.

\begin{tabular}{ll}
\hline Ideias centrais & Discurso do sujeito coletivo \\
\hline IC 11: Aqui nós não conversamos & DSC 11: "Eu acho importante até um ano de idade. Eu sei, porque eu amamentei, mas \\
sobre AM com as mães & nunca cheguei a conversar com nenhuma mãe sobre isso." \\
\hline
\end{tabular}

IC: Ideia Central; DSC: Discurso do Sujeito Coletivo; AM: aleitamento materno

A IC 11 traz a realidade desses profissionais que nada fazem para a promoção, incentivo e manutenção do aleitamento, mesmo considerando uma prática importante. Essa realidade pode ser justificada pela ausência de esclarecimentos e ensinamentos específicos nos cursos de licenciatura, pois não há disciplina característica que aborde o tema da alimentação infantil, mesmo com a existência de tantas políticas públicas buscando o sucesso dessa prática ${ }^{(4,35)}$.

A última questão norteadora diz respeito à relação das profissionais com a mãe que amamenta e se conversam sobre expectativas e experiências da amamentação (Tabela V). 
Tabela V - Apresentação das ideias centrais e Discursos do Sujeito Coletivo sobre o diálogo e relacionamento entre a profissional e a mãe que amamenta. Foz do Iguaçu, Paraná, Brasil, 2015.

Ideias centrais
IC 12: Os pais não têm tempo
IC 13: Incentivo à introdução
alimentar

\section{Discurso do sujeito coletivo}

DSC 12: "Não ocorre. Nosso contato com os pais é mínimo, elas estão sempre com pressa. Muito difícil, mas são poucas situações de mãe que ainda amamentam."

DSC 13: "Não falamos sobre isso por chegarem com mais de seis meses. A gente instrui que ela ofereça em casa algo semelhante à alimentação do $\mathrm{CMEl}$, evite amamentar no horário que a criança fica no CMEI, mesmo nos fins de semana, e pedimos para que dê o leite materno na mamadeira, pra que ele se acostume com o bico e aceite depois o leite de vaca do CMEI. Nós colocamos o cardápio no caderno para os pais. A fala sobre aleitamento é só quando há problema na aceitação da alimentação. Não orientamos a retirar o peito, mas não incentivamos."

IC: Ideia Central; DSC: Discurso do Sujeito Coletivo

A maior parte das entrevistadas afirmou na IC 12 que falta tempo para diálogos com a mãe e a família da criança. Um estudo sobre a formação dos educadores infantis indicou que, entre seus participantes, a maior dificuldade de atuação estava relacionada, primeiramente, aos pais dos alunos e sua comunicação. Nesse relacionamento frágil, a maioria das educadoras não sente o reconhecimento dos pais e familiares pelo seu bom desempenho no trabalho com seus filhos, configurando uma relação problemática, na qual educadoras e família avaliam mutuamente seus cuidados sobre a criança ${ }^{(36)}$.

$\mathrm{Na}$ IC 13, encontrou-se o incentivo à introdução alimentar. Perante a família, a creche é um ambiente confiável, acreditando que será ofertada à criança uma ótima educação, uma alimentação farta, saudável e um ambiente seguro. Entretanto, estudos têm apontado que existe uma prevalência de baixa estatura, sobrepeso, insegurança alimentar, anemia, deficiência de zinco e parasitismo entre crianças assistidas em creches $^{(37-39)}$. Como algumas dessas condições poderiam ser evitadas com uma maior duração do aleitamento materno exclusivo, faz-se necessário que a equipe de saúde reveja as estratégias educacionais para mães e profissionais das creches sobre alimentação complementar ${ }^{(14,40)}$.

As instituições escolares precisam ser vistas como espaços onde é possível o desenvolvimento de ações para favorecer o aleitamento materno. O tema ainda não foi suficientemente abordado e valorizado pelos profissionais de saúde em termos de pesquisa no ambiente escolar. Assim, seus aspectos são pouco explorados. Esse assunto necessita receber maior atenção por parte não só dos pesquisadores, mas também da sociedade como um todo.

Como limitação, esta pesquisa não representa a atuação dos CMEIS em sua totalidade, visto que apenas se estudou um município brasileiro e que aspectos culturais, educacionais e socioeconômicos devem ser considerados para a construção da percepção das profissionais da educação.

\section{CONSIDERAÇÕES FINAIS}

As profissionais da educação investigadas consideram que o centro municipal de educação infantil não é um bom lugar para a prática do aleitamento materno e, dentre as dificuldades para as mães amamentarem na instituição, estão: atrapalha a rotina estabelecida; dificulta o desmame precoce e a adaptação; falta sala de amamentação; a mãe não consegue sair do trabalho ou ele se localiza a uma grande distância; desperta outras crianças para o leite materno e lembranças olfativas da sua mãe. Portanto, apesar de saberem os aspectos positivos, estes são enterrados pelas dificuldades. Desse modo, para a realidade posta, não se verifica a promoção do aleitamento materno, como preconizado pela OMS e pelo Ministério da Saúde.

Mas, acima de tudo, fica latente uma preocupação com a saúde das crianças que frequentam as salas de berçário: a falta de diálogo entre pais e profissionais da educação, o desmame precoce, a alta probabilidade de contraírem infecções e outros agravos característicos da faixa etária, principalmente quando comparadas com aquelas que são cuidadas exclusivamente em casa.

Mais estudos serão necessários para compreender o alcance de toda esta exposição aos diferentes determinantes de saúde e suas implicações de saúde na vida adulta. Não é, contudo, preciso comprovar com resultados negativos para que agravos à saúde desses pequenos cidadãos sejam evitados, pois é bem conhecido que a prevalência da amamentação é determinante para a diminuição da morbimortalidade infantil. 


\section{CONFLITOS DE INTERESSE}

Os autores informam que não há conflitos de interesse.

\section{CONTRIBUIÇÕES}

Bianca da Silva Alcântara Pereira e Adriana Zilly participaram da concepção, planejamento, análise, interpretação dos dados e revisão do manuscrito. Elisangela Bellafronte, Maria de Lourdes de Almeida, Roseane Meire Munhak da Silva e Reinaldo Antônio Silva Sobrinho contribuíram para a revisão do manuscrito.

\section{REFERÊNCIAS}

1. Boccolini CS, Boccolini PMM, Monteiro FR, Venancio SI, Giugliani ERJ. Tendência de indicadores do aleitamento materno no Brasil em três décadas. Rev Saúde Pública. 2017;51:108.

2. Maia EM, Santiago LB, Sampaio ACF, Lamounier JA. Programa de apoio ao aleitamento materno exclusivo para mães trabalhadoras da iniciativa privada. Rev Med Minas Gerais. 2015;25(1):19-24.

3. Victora CG, Bahhl R, Barros AJD, França GVA, Horton S, Kraseyec J, et al. Breastfeeding in the 21st century: epidemiology, mechanisms and lifelong effect. Lancet. 2016;387(10017):475-90.

4. Souza MHN, Sodre VRD, Silva FNF. Prevalência e fatores associados à prática da amamentação de crianças que freqüentam uma creche comunitária. Cienc Enferm. 2015;21(1):55-67.

5. Brasileiro AA, Ambrosano GMB, Marba STM, Possobon RF. Breastfeeding among children of women workers. Rev Saúde Pública. 2012;46(4):642-8.

6. Prefeitura Municipal de Foz do Iguaçu-Paraná. Secretaria Municipal de Educação [acesso em 2015 Fev 20]. 2014. Disponível em: http://www.pmfi.pr.gov.br/Portal/VisualizaObj.aspx?IDObj=13572

7. Lefevrè $F$, Lefevrè $A M C$. Pesquisa de representação social: um enfoque qualiquantitativo: a metodologia do discurso do sujeito coletivo. $2^{\mathrm{a}}$ ed. Brasília: Liberlivro; 2012.

8. Martins GDF, Becker SMS, Leão LCS, Lopes RCS, Piccinini CA. Fatores associados a não adaptação do bebê na creche: da gestação ao ingresso na instituição. Psicol Teor Pesqui. 2014;30(3):241-50.

9. Ministério da Saúde (BR), Secretaria de Atenção à Saúde, Departamento de Atenção Básica. Saúde da criança: aleitamento materno e alimentação complementar. $2^{\mathrm{a}}$ ed. Brasília: Ministério da Saúde; 2015.

10. Brasil. Consolidação das Leis do Trabalho. Decreto-lei $n^{\circ} 5.452$, de $1^{\circ}$ de maio de 1943. [acesso em 2018 Maio 23]. Disponivel em: http://www.trtsp.jus.br/geral/tribunal2/LEGIS/CLT/TITULOIII.html

11. Wilhelm LA, Demori CC, Alves CN, Barreto CN, Cremonese L, Ressel LB. A vivência da amamentação na ótica de mulheres: contribuições para a enfermagem. Rev Enferm UFSM. 2015;5(1):160-8.

12. Rocha MG, Costa ES. Interrupção precoce do aleitamento materno exclusivo: experiência com mães de crianças em consultas de puericultura. Rev Bras Promoç Saúde. 2015;28(4):547-52.

13. Araújo NL, Lima LHO, Oliveira EAR Carvalho ES, Dualibe FT, Formiga LMF. Alimentação dos lactentes e fatores relacionados ao aleitamento materno. Rev Rene. 2013;14(6):1064-72.

14. World Health Organization. Implementation guidance: protecting, promoting and supporting breastfeeding in facilities providing maternity and newborn services: the revised baby-friendly hospital initiative. Geneva: WHO; 2018.

15. Barbieri MC, Bercini LO, Brondani KJM, Ferrari RAP, Tacla MTGM, Sant'anna FL. Aleitamento materno: orientações recebidas no pré-natal, parto epuerpério. Semina Ciênc Biol Saúde. 2015;36(1):17-24.

16. Andrade ISN. Aleitamento materno e seus benefícios: primeiro passo para a promoção saúde. Rev Bras Promoç Saúde. 2014;27(2):149-50.

17. Goergen IB, Bosco SMD, Adami FS. Relação entre o peso ao nascer e o tempo de aleitamento materno com o estado nutricional atual de crianças. Rev Bras Promoç Saúde. 2015;28(3):344-50. 
18. Pudla KJ, Gonzaléz-Chica DA, Vasconcelos FAG. Efeito do aleitamento materno sobre a obesidade em escolares: influência da escolaridade da mãe. Rev Paul Pediatr. 2015;33(3):294-301.

19. Pomiecinski F, Guerra VMCO, Mariano REM, Landim RCSL. Estamos vivendo uma epidemia de alergia alimentar? Rev Bras Promoç Saúde. 2017;30(3):1-3.

20. Bossi TJ, Soares E, Lopes RCS, Piccinini CA. Adaptação à creche e o processo de separação-individuação: reações dos bebês e sentimentos parentais. Psico. 2014;45(2):250-60.

21. Souza JPO, Prudente AM, Silva DA, Pereira LA, Rinaldi AEM. Avaliação do conhecimento de funcionárias de escolas municipais de educação infantil sobre aleitamento materno e alimentação complementar. Rev Paul Pediatr. 2013;31(4):480-7.

22. Braga NP, Rezende MA, Fujimori E. Amamentação em creches no Brasil. Rev Bras Crescimento Desenvolv Hum. 2009;19(3):465-74.

23. Warkentin S, Viana KJ, Zapana PM, Taddel JAAC. Fatores associados à interrupção do aleitamento materno exclusivo. J. Brazilian Soc Food Nutr. 2012:37(2):105-17.

24. Brasil. Estatuto da Criança e do Adolescente: Lei 8.069/90, de 13 de Julho de 1990. Brasília: Senado Federal; 1990.

25. Brasil. Constituição (1988). Constituição da República Federativa do Brasil: promulgada em 5 de outubro de 1988. Brasília, 1988.

26. São Paulo. Secretaria Municipal de Educação. Projeto de Lei $416 / 2016$ que estabelece diretrizes aos centros educacionais infantis para permitir o aleitamento materno [acesso em 2018 Maio 23]. Disponível em: https:// www.imprensaoficial.com.br/Certificacao/GatewayCertificaPDF.aspx?notarizacaolD=408ac142-58e7-4f49-a19a8388d630bf1a

27. Martins RJ, Gonçalves TM. Apropriação do espaço na pré-escola segundo a psicologia ambiental. Psicol Soc. 2014;26(3):622-31.

28. Secretaria de Estado da Saúde do Paraná. Resolução SESA nº 0162, de 14 de fevereiro de 2005. Estabelece normas técnicas para os Centros de Educação Infantil. Curitiba: SESA; 2005.

29. Peres PLP, Pegoraro AO. Condições desiguais como causas para a interrupção do aleitamento. Rev Enferm UERJ. 2014;22(2):278-85.

30. Addati L, Cassirer N, Gilchrist K. Maternity and paternity at work: law and practice across the world. Geneva: National Labour Office; 2014.

31. Rollins NC, Bhandari N, Hajeebhoy N, Horton S, Lutter CK, Martines JC, et al. Why invest, and what it will take to improve breastfeeding practices? Lancet. 2016;387(10017):491-504.

32. Machado JS, Cechim PLR. Aleitamento materno exclusivo. Motivações e desmotivações das nutrizes de Eldorado do Sul (Brasil). Invest Educ Enferm. 2013;31(3):377-84.

33. Ribeiro JRIS. A percepção dos pais sobre as competências dos bebés [dissertação]. Lisboa: Instituto Universitário de Psicologia Aplicada; 2011.

34. Leal ARL. O ensino bilíngue na creche internacional curumim: uma experiência prática com crianças até 3 anos. EntreVer. 2013;3(5):64-75.

35. Secretaria de Estado da Educação do Paraná, Superintendência da Educação, Departamento de Educação e Trabalho. Orientações Curriculares para o Curso de Formação de Docentes da Educação Infantil e Anos Iniciais do Ensino Fundamental, em Nível Médio, na Modalidade Normal. Curitiba: SEED/PR; 2014.

36. Nylander PIA, Santos RCB, Magalhães LS, Afonso T, Cavalcante LIC. Educadores infantis: aspectos da formação profissional e do trabalho em creche. Temas Psicol. 2012;20(2):666-77.

37. Oliveira TSC, Silva MC, Santos JN, Rocha DS, Alves CRL, Capanema FD, et al. Anemia entre pré-escolares: um problema de saúde pública em Belo Horizonte, Brasil. Ciênc Saúde Colet. 2014;19(1):59-66.

38. Pedrasa DF, Queiroz D, Sales MC. Doenças infecciosas em crianças pré-escolares brasileiras assistidas em creches. Ciênc Saúde Colet. 2014;19(2):501-18. 
39. Pedrasa DF. Linear growth of children attending public day care centers in the municipality of Campina Grande, Paraíba, Brazil. Rev Bras Epidemiol. 2016;19(2):451-63.

40. Longo-Silva G, Silveira JAC, Menezes RCE, Toloni MHA. Age at introduction of ultra-processed food among preschool children attending day-care centers. J Pediatr (Rio de J). 2017;93(5):508-16.

\section{Endereço do primeiro autor:}

Bianca da Silva Alcântara Pereira

Escola de Enfermagem de Ribeirão Preto - EERP

Av. dos Bandeirantes, 3900

Campus Universitário

Bairro: Monte Alegre

CEP: 14040-902 - Ribeirão Preto - SP - Brasil

E-mail: biancalcantara@msn.com

\section{Endereço para correspondência:}

Elisangela Bellafronte

Universidade Estadual do Oeste do Paraná - UNIOESTE

Av. Tarquínio Joslim dos Santos, 1300

Bairro: Jardim Universitário

CEP: 85870-650 - Foz do Iguaçu - PR - Brasil

E-mail:e_bio79@yahoo.com.br 